\title{
Announcement: PRC Editors' Suggestions
}

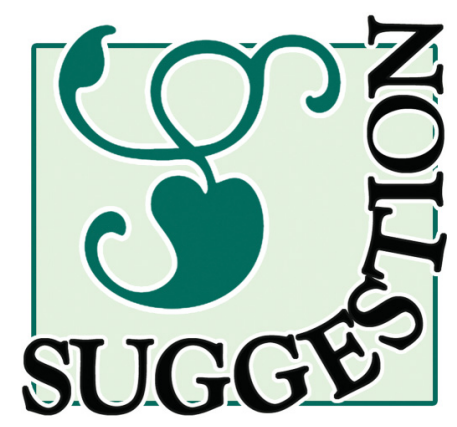

As a service to our readers, starting July 1 we will formally mark a small number of papers published in Physical Review $C$ that the editors and referees find of particular interest, importance, or clarity. This follows the feature begun by Physical Review Letters in January 2007 and continued by Physical Review B in April 2008. These Editors' Suggestion papers will be listed on prc.aps.org and marked with a special icon in the print and online Tables of Contents and in online searches. The icon contains the printer's mark that at one time appeared on the covers of all sections of the Physical Review.

Published 2 July 2012

DOI: 10.1103/PhysRevC.86.010001

PACS number(s): 01.10.Cr, 01.30.-y 